\title{
CONTROLE BIOLÓGICO DO ÁCARO RAJADO COM ÁCAROS PREDADORES FITOSEÍDEOS (ACARI: TETRANYCHIDAE, PHYTOSEIIDAE) EM CULTURAS DE PEPINO E MORANGO
}

\author{
M.A. WATANABE; G.J. de MORAES; I. GASTALDO Jr.; G. NICOLELLA \\ EMBRAPA/CNPMA, C.P. 69 - CEP: 13829-000 - Jaguariana,SP.
}

\begin{abstract}
RESUMO: $O$ ácaro rajado, Tetranychus urticae Koch, é considerado uma das principais pragas de hortaliças e várias outras culturas no Brasil, em áreas onde um considerável volume de acaricidas é anualmente empregado no seu controle. $O$ objetivo deste trabalho foi testar a viabilidade técnica do emprego dos fitosefdeos Amblyseius idaeus (Denmark \& Muma) e Phytoseiulus macropilis (Banks), comumente encontrados no Brasil, no controle de T. urticae em pepino e morangueiro em Jaguariúna,SP. Utilizou-se o delineamento experimental em blocos casualizados, com 4 repetiç̃es e 4 tratamentos (T1-T4) para o pepino e 5 tratamentos para o morangueiro (T1-T5): T1, testemumha; T2, pulverizaçōes semanais de Malation para a exclusão de predadores nativos; $T 3$, liheraçбes perídicas de $A$.idaeus; T4, liberaçðes perídicas de $P$.macropilis; T5, pulverizą̧⿸̃es semanais de avermectina para a exclusão de ácaros fitofagos e predadores nativos. Apenas A.idaeus se estabeleceu na cultura de pepino, reduxindo significativamente a população de $T$. urticae. Ambas especies de predadores se estabeleceram na cultura do morango e reduziram significativamente a população de T.urticae.
\end{abstract}

Descritores: ácaro rajado, Tetranychus urticae, Phytoseidae, Amblyselus idaeus, Phytoseiulus macropiltis, pepino, Cucumis sativus, morango, Fragaria vesca.

\section{BIOLOGICAL, CONTROL OF TIIE TWOSSPOTTED SPIDER MITE (ACARI: TETRANYCIDAE, PITTOSEIDAE) IN CUCUMBER AND STRAWBERRY CROPS}

\begin{abstract}
The two-spotted spider mite, Tetranychus urticae Koch, is considered one of the main pests of horticultural and other crops in Brazil, in areas where a considerable volume of acaricides is annually used for its control. The objective of this work was to test the technical viability of using phytoseiids Amblyseius idaeus (Denmark \& Muma) and Phytoselulus macroplls (Banks), commonly found in Brazil, to control T.urticae in cucumber and strawberry crops in Jaguariuina,SP. A randomized complete block design was used, with 4 replicates and 4 treatments for cucumber (T1-T4) and 5 treatments for strawberry crops (T1-T5): T1, control; T2, weekly sprays of malathion for exclusion of native predators; T3, periodical releases of A.idaeus; T4, periodical releases of $P$. macropilis; T5, weekly sprays of avermectin for exclusion of native phytophagous and predatory mites. Only $A$. idaeus was successfully established on cucumber, significantly reducing $T$. urticae population. Both released phytoseiid species were established on strawberry and reduced significantly the population of $T$. urticae.

Key words: two-spotted spider mite, Tetranychus urticae, Phytoseidae, Amblyseius idaeus, Phytoseiulus macropilis, cucumber, Cucumis sativus, strawberry, Fragaria vesca.
\end{abstract}

\section{INTRODUÇÃo}

0 ácaro rajado, Tetranychus urticae Koch, tem causado consideráveis prejuízos em diversas culturas no Brasil (FLECHTMANN, 1985). Seu controle vem sendo realizado exclusivamente com o uso de pesticidas químicos, cujo impacto ambiental, sob certas circunstâncias, pode ser bastante significativo. Em diversos países da Europa e na América do Norte seu controle é frequentemente realizado através de liberações periódicas de ácaros predadores da famúlia Phytoseiidae (HELLE \& SABELIS, 1985).

A partir do final da década de 1950, os ácaros fitoseídeos passaram a ser extensivamente reconhecidos como eficientes predadores de ácaros fitófagos (McMURTRY et al., 1970). Desde então seu emprego no controle $T$. urticae vem sendo 
testado em diversos países (HELLE \& SABELIS, 1985), principalmente em pepino, morango e ormamentais. Trabalhos conduzidos no Brasil, na região de Botucatu, São Paulo, têm demonstrado a potencialidade de se realizar o controle biológico de $T$. urticae em morango com a liberação de predadores (GARCIA, 1992). Ainda que importantes tentativas ja tenham sido realizadas (MORAES, 1991), não se pode dizer que sua viabilidade técnica seja adequadamente conhecida em nosso país. MORAES (1992) considerou como promissora a possibilidade de se utilizar ácaros fitoseídeos no controle desta praga. $O$ presente trabalho teve como objetivo testar a viabilidade técnica do emprego dos fitoseídeos Amblyseius idaeus (Denmark \& Muma) e Phytoseiulus macropilis (Banks) no controle do T. urticae em pepino e morango.

\section{MATERIAIS E MÉTODOS}

Este trabalho foi realizado na Campo Experimental do Centro Nacional de Pesquisa de Monitoramento e Avaliação de Impacto Ambiental (CNPMA/EMBRAPA), em Jaguariúna, São Paulo, no período de janeiro a outubro de 1992. As culturas de pepino e morango foram conduzidas utilizando-se os tratos culturais comumente empregados pelos agricultores da região.

Os ácaros predadores A.idaeus e P.macropilis foram criados no Laboratório de Entomologia do CNPMA/EMBRAPA, a partir de indivíduos recentemente coletados de cultura de mandioca em Petrolina, Pernambuco e em cultura de algodão em Campinas,SP, respectivamente. 0 processo de criação utilizado foi uma adaptação daquele proposto por MCMURTRY \& SCRIVEN (1965). Desta forma, uma criação de T.urticae foi realizada sobre plantas de feijão-de-porco, Canavalia ensiformes L., mantidas em casa-telada. Ovos destes ácaros foram periodicamente coletados e fornecidos como alimento aos predadores. $\mathrm{Na}$ Época da liberação, os predadores foram coletados em canudos plásticos de refrigerante, que foram fixados a pecíolos de folhas de pepino e morango.

Cultura de Pepino: Utilizou-se a cultivar 'Cometa', no espaçamento de $1,0 \times 0,5 \mathrm{~m}$, sendo cada parcela composta por um total de 60 plantas. O transplante das mudas ao campo definitivo foi realizado em 4 de fevereiro. Area útil correspondeu às 4 fileiras centrais, exceto as plantas dos extremos. A distância entre as parcelas foi de $2,0 \mathrm{~m}$.
Linhas de milho (Zea mays L.) foram plantadas entre as parcelas para se evitar a dispersão dos ácaros entre elas. Realizaram-se 3 pulverizaçōes semanais dos fungicidas benomil para o controle de antracnose (Colletotrichum gloesporioides f. sp. cucurbitae (Berk et Mont) Menten et Kimati), e de pulverização semanal de Bacillus thuringiensis Berliner para o controle da broca das cucurbitáceas (Diaphania spp.).

Para se homogeneizar a distribuição de T. urticae no campo, realizou-se no dia 10 de março uma liberação de 10 fêmeas desta espécie em cada uma de $\mathbf{2 0}$ folhas jovens determinadas ao acaso em cada parcela. Seis dias mais tarde, liberaram-se 8 fêmeas de predadores nas mesmas folhas previamente infestadas por $T$.urticae.

Cultura de Morango: Utilizou-se a cultivar 'Princesa Isabel' no espaçamento de $0,3 \times 0,25 \mathrm{~m}$, sendo cada parcela composta por um total de 132 plantas. O transplante das mudas ao campo definitivo foi realizado em 7 de abril. A área útil correspondeu às 2 fileiras centrais, exceto as plantas das extremidades. Após o pegamento das mudas, as parcelas foram cobertas com lona plástica preta para manutenção da umidade do solo e controle de invasoras. A distância entre as parcelas foi de $1,0 \mathrm{~m}$.

Para se reduzir a dispersão dos ácaros, plantaram-se neste espaço faixas de $0,2 \mathrm{~m}$ de aveia preta (Avena strigosa Sereb), as quais foram mantidas durante todo o experimento. Durante este período, realizaram-se aplicações semanais do fungicida tebuconazole para o controle de micosferela (Mycosphaerella fragariae (Tul.) Lind.). Após o início do amadurecimento dos frutos, realizaram-se 2 colheitas semanais até o final do experimento.

Também nesta cultura fez-se a infestação com T.urticae, liberando-se no dia 9 de junho 5 fêmeas desta espécie em cada uma de 20 folhas jovens determinadas ao acaso em cada parcela, exceto naquelas correspondentes ao tratamento T5. Dezesseis dias mais tarde (25 de junho), liberaram-se 4 fêmeas de predadores nas mesmas folhas previamente infestadas por T.urticae. Uma nova liberação de predadores sobre as mesmas folhas foi realizada $\mathbf{2 6}$ dias mais tarde (21 de julho). No dias 4 de agosto e 18 de agosto, novas liberações de predadores foram realizadas, colocando-se 6 predadores por folha (já na folha nova). No dia 9 de setembro, foram liberados 5 A.idaeus por folha. 
Delineamento experimental e avaliações: Utilizou-se o delineamento experimental em blocos casualizados com 4 repetições e 4 tratamentos para o pepino (T1 a T4) e 5 tratamentos para o morangueiro (T1 a T5): T1, testemunha; T2, pulverizações semanais de malation para a exclusão de predadores nativos; T3, liberações periódicas de $A$. idaeus; T4, liberações periódicas de P.macropilis; T5, pulverizações semanais de avermectina para a exclusão de ácaros fitófagos e predadores nativos.

Avaliações dos níveis populacionais dos ácaros foram iniciadas 3 dias após a liberação de T. urticae e continuadas semanalmente até o final do experimento. Estas foram feitas contando-se no campo o número das formas ativas destes ácaros com o auxílio de lupas de bolso $(10 \mathrm{x})$ em cada uma das folhas onde as liberações haviam sido previamente realizadas. Na cultura de pepino, o número de ácaros foi avaliado considerando-se 5 pontos $\left(1 \mathrm{~cm}^{2}\right)$ da face inferior da folha inicialmente infestada. Na cultura do morango, o número de ácaros foi avaliado em toda a face ventral dos 3 foliolos de cada folha. Devido ao longo período de amostragem e ao envelhecimento das folhas de morango onde os ácaros foram inicialmente liberados, as avaliações foram feitas sobre estas folhas até o dia $\mathbf{3 1}$ de julho, e na folha imediatamente mais jovem a partir de então.

\section{RESULTADOS}

Cultura de Pepino: Os predadores aparentemente se dispersaram para outras folhas logo após sua liberação no campo. Dos 8 predadores liberados em cada folha, apenas 1,7 A.idaeus e 0,2 $P$.macropilis foram encontrados em média em cada uma destas, 4 dias mais tarde (Figura 2). $O$ número de $A$.idaeus decresceu a cerca de 1,0 por folha no final do período de observação, enquanto P.macropilis não foi mais encontrado naquela ocasião. Um número muito reduzido de fitoseídeos nativos $(0,05$ por folha) foi encontrado nas avaliações realizadas em 20 de março e 1 de abril. Estes ácaros atingiram níveis consideravelmente mais baixos que aqueles alcançados pelas espécies liberadas. As espécies encontradas e suas respectivas freqüências relativas foram Amblyseius aripo (DeLeon) 70\%, Amblyseius mexicanus (Garman) 13\%, Amblyseius anonymus Chant \& Baker 9\%, Amblyseius mangleae (DeLeon) 4\% e Amblyseius n. sp. $4 \%$. Nenhum predador nativo foi encontrado em outras contagens.
A primeira avaliação realizada após a liberação de T.urticae e antes da liberação dos predadores não indicou diferenças significativas entre os tratamentos (Figura 1). Logo após a liberação dos fitoseídeos, o tratamento T3 (liberação de A.idaeus) destacou-se dos demais tratamentos, apresentando número de T.urticae significativamente menor (teste de Duncan, $5 \%$ de probabilidade). Esta diferença mostrou-se significativa durante todo o período de avaliação (teste de Duncan a $5 \%$ de probabilidade). Ao final deste periodo, o número de T.urticae foi cerca de 4 vezes menor no tratamento T3 que nos outros tratamentos. Os demais tratamentos apresentaram aproximadamente os mesmos níveis de T.urticae. A.idaeus mostrou-se muito mais promissor que P.macropilis no controle de T.urticae em pepino. Este fato foi um tanto surpreendente, tendo em vista que uma outra espécie deste mesmo gênero (Phytoseiulus persimilis Athias-Henriot) é a mais utilizada em nível mundial no controle biológico desta praga (McMURTRY, 1991).

Os predadores nativos não se mostraram eficientes neste experimento, o que pode ser parcialmente devido ao efeito sobre estes predadores dos pesticidas utilizados no estudo ou à sua capacidade inerentemente baixa de responder numericamente a um aumento da população de T.urticae, especialmente neste caso, que envolveu a inoculação proposital deste último. Pouco se sabe sobre os aspectos biológicos e ecológicos das espécies encontradas, exceto com relação a A.anonymus, que tem sido estudado devido ao interesse por esta espécie em relação a seu uso para o controle biológico de tetraniquídeos em mandioca (MESA \& BELLOTTI, 1988; GONDIM Jr., 1992).

Cultura de Morango: Também nesta cultura os predadores aparentemente se dispersaram após a liberação, tendo o número de $A$.idaeus reduzido a 0,8 e o número de $P$.macropilis reduzido a 1,5 ácaros por folha na primeira contagem, realizada 6 dias após a liberação de T.urticae, isto É, em 1 de julho (Figura 3). Estes números se mantiveram aproximadamente constantes até a terceira contagem. A partir de então, a população de A.idaeus passou a aumentar, atingindo cerca de 3,2 indivíduos por folha no final de agosto e cerca de 4,0 indivíduos por folha no final do experimento (início de setembro). A população de P.macropilis atingiu o nível máximo no início de agosto $(5,7$ indivíduos por folha), diminuindo a partir desta época. 


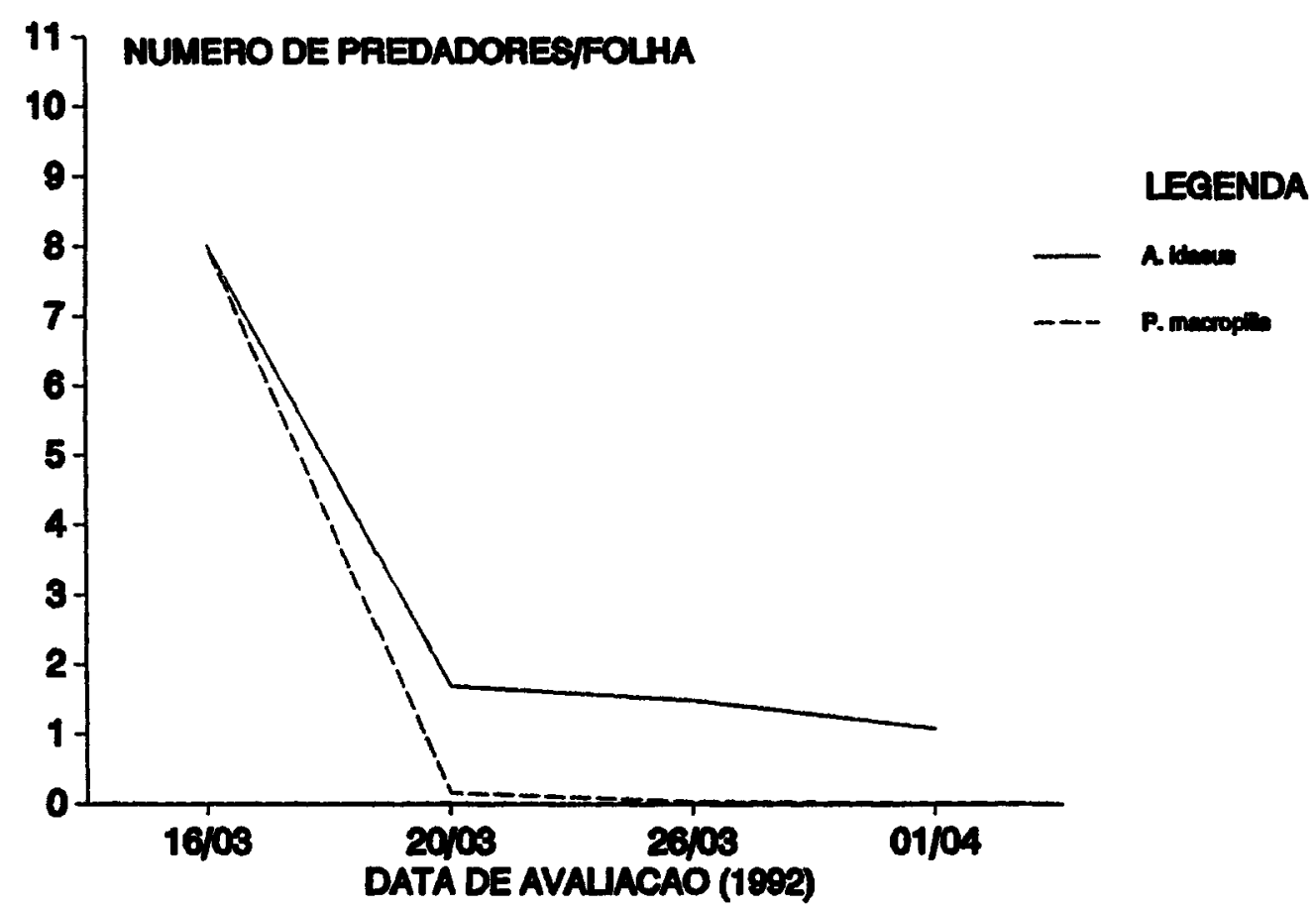

Figura 1 - Número de predadores por folha em cultura de pepino.

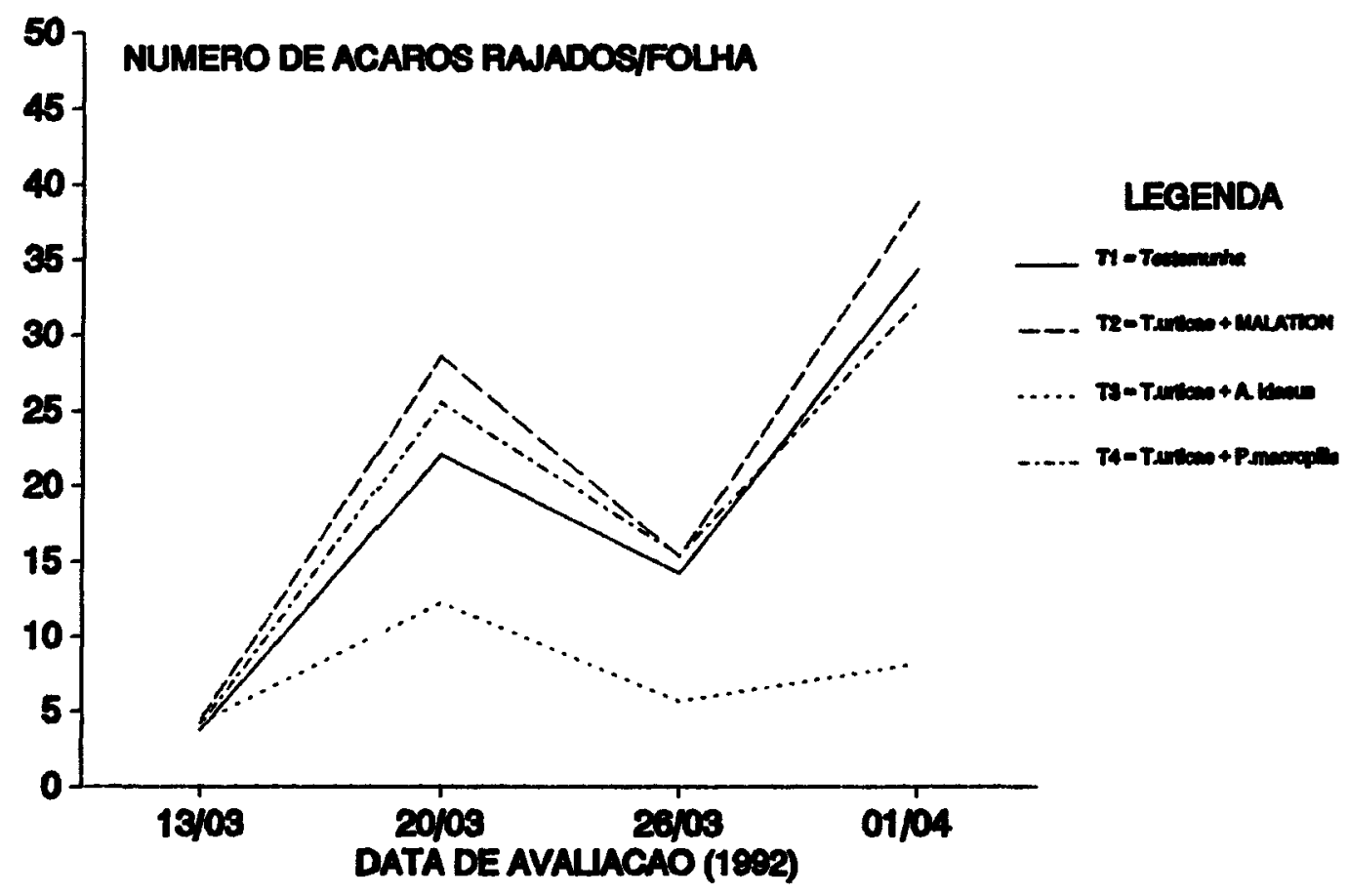

Figura 2 - Número de acaros rajados por folha em cultura de pepino.'

Sci. agric., Piracicaba, T51(1):75-81, jan./abr., 1994 


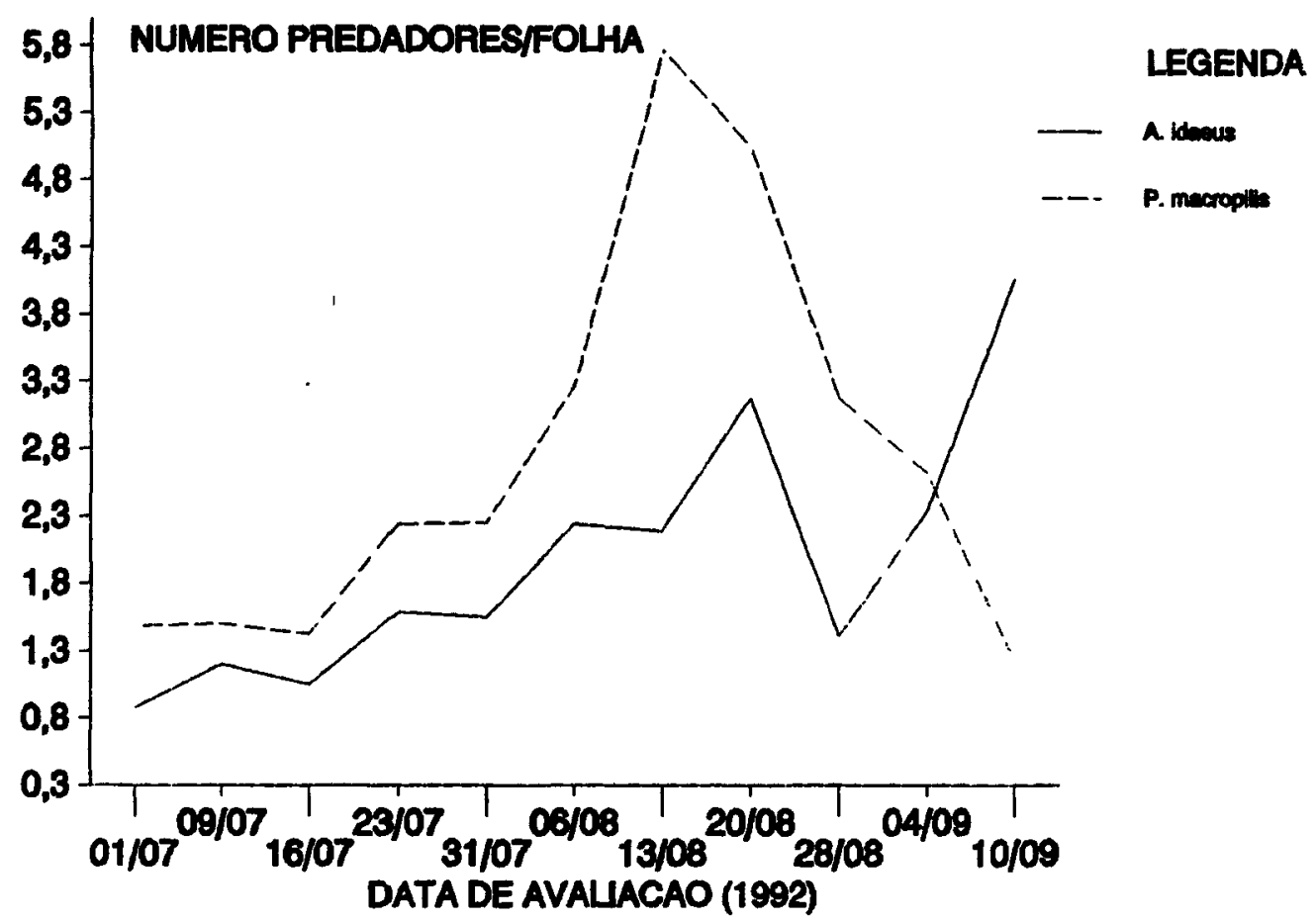

Figura 3 - Número de ácaros predadores por folha em cultura de morango.

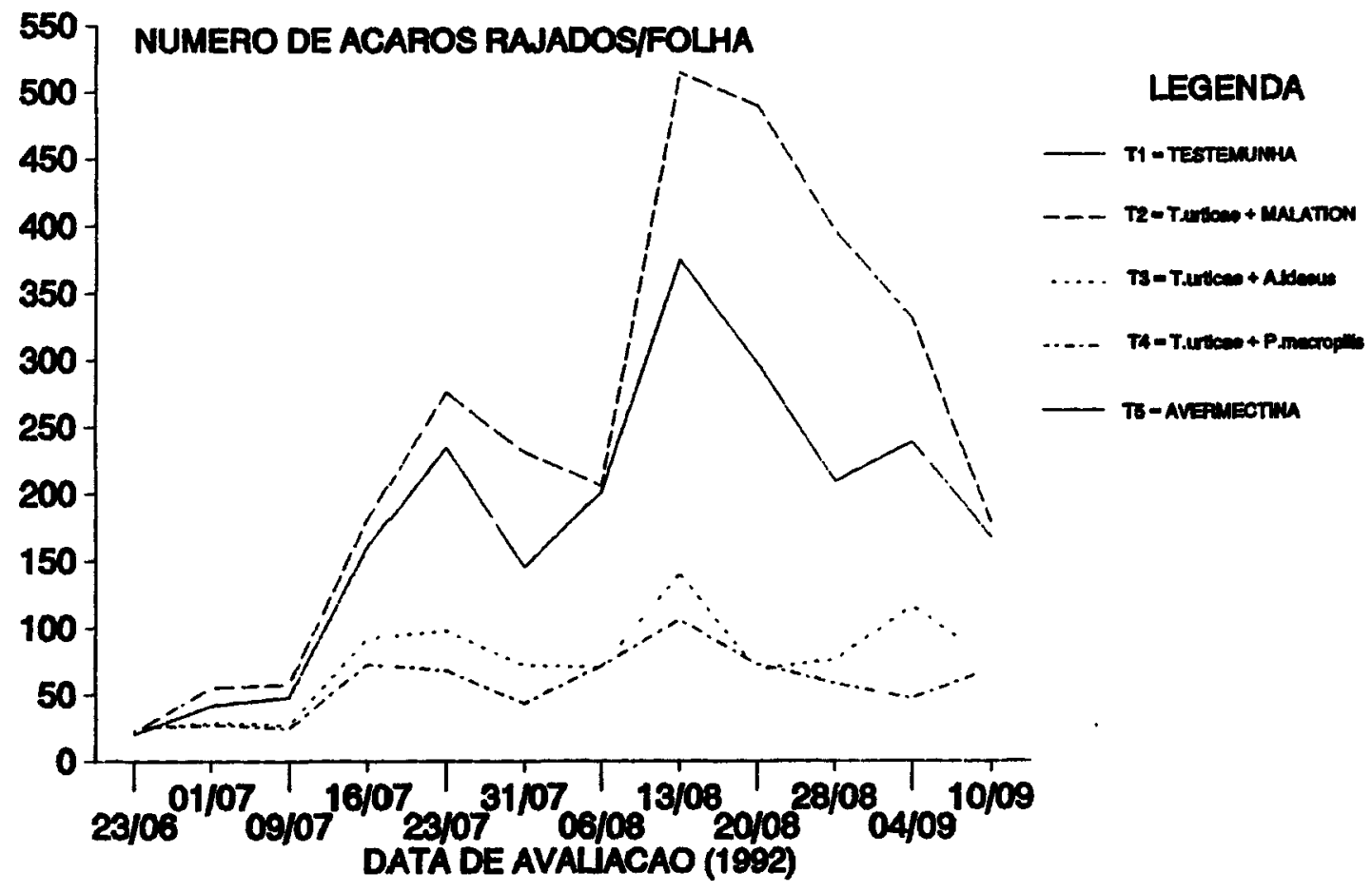

Figura 4 - Número de ácaros rajados por folha em cultura de monrago.

Sci. agric., Piracicaba, v.51(1):75-81, jan./abr., 1994 
TABELA 1 - Produção de frutos de morango (g/planta) sob diferentes tratamentos ${ }^{1}$. Jaguariúna,SP, 1992.

\begin{tabular}{cccccc}
\hline & \multicolumn{5}{c}{ Tratamentos $^{2}$} \\
\cline { 2 - 7 } & 1 & 2 & 3 & 4 & 5 \\
\hline Produção & 694 & 675 & 775 & 717 & 679 \\
\hline \hline
\end{tabular}

1) Não houve diferença estatisticamente significativa entre os tratamentos ao nível de $5 \%$ de probabilidade (teste de Duncan).

2) T1, testemunha; T2, exclusão de predadores nativos; $T 3$, liberação do predador A.idaeus; T4, liberação do predador P.macropilis; T5, exclusão de fitófagos e predadores nativos.

No final do experimento, o nível de $P$.macropilis foi de 1,2 indivíduos por folha. $O$ número de predadores nativos atingiu níveis máximos em 16 de julho e 13 de agosto (cerca de 0,4 e 0,3 indivíduos por folha, respectivamente).

Assim como na cultura de pepino, estes niveis foram consideravelmente menores que aqueles das espécies liberadas. As espécies encontradas e suas respectivas freqüências relativas foram Amblyseius californicus (McGregor) 54\%, A. anonymus 38\%, A.cannaensis (Muma) $8 \%$.

Em todos os tratamentos, os níveis máximos de T.urticae foram alcançados no início de agosto (Figura 3). Os níveis mais altos corresponderam ao tratamento T2 (pulverizações periódicas de malation), seguido do tratamento $\mathrm{T} 1$ (testemunha) (diferenças estatisticamente significativas em 31 de julho, 20 e 28 de agosto - teste de Duncan, 5\% de probabilidade). As parcelas onde foram liberados os fitoseídeos apresentaram sempre um número significativamente menor de $T$. urticae (teste de Duncan, $5 \%$ de probabilidade). Notou-se também que em quase todas as avaliações o número de T.urticae foi um pouco menor nas parcelas que receberam $P$.macropilis que aquelas que receberam A.idaeus, embora estas diferenças não tenham se mostrado estatisticamente significativas.

As mesmas proporções entre os níveis dos ácaros nos distintos tratamentos foram observadas nas folhas onde as liberações haviam sido originalmente realizadas $e$ nas folhas que passaram a ser avaliadas a partir de 6 de agosto (Figuras 3 e 4). Os níveis consistentemente mais baixos de $T$.urticae no tratamento $T 1$ que no tratamento $\mathrm{T} 2$ indicam o efeito significativo dos predadores nativos sobre aquele ácaro. Entretanto, este efeito não pode evitar que o nível de $T$. urticae atingisse mais de 350 ácaros por folha, isto é, mais de 110 ácaros por folíolo em 13 de agosto.

Apesar dos elevados níveis atingidos por T.urticae, não se observaram diferenças significativas de produção de frutos entre os tratamentos (TABELA 1). Isto indica a grande tolerância da cultivar 'Princesa Isabel' ao ataque deste ácaro.

\section{DISCUSSÃO}

Pouco se sabe sobre o comportamento e a potencialidade de A.idaeus como inimigo natural de T.urticae. Praticamente tudo que se conhece sobre este predador se deve ao interesse de se introduzir esta espécie na África para o controle biológico do tetraniquídeo Mononychellus tanajoa (Bondar) em cultura de mandioca (YANINEK et al., 1991). A.idaeus foi descrita a partir de exemplares coletados em Piracicaba, São Paulo (DENMARK \& MUMA, 1973), sendo mais tarde encontrado em vários estados brasileiros e também em outros países da América do Sul (MORAES et al., 1986).

Estudos da biologia de A.idaeus indicaram comportamentos bastante diferentes de distintas populações desta mesma espécie (ARAUJO et al., 1991). Isto indica a possibilidade de se conseguir populações desta espécie que sejam ainda mais eficientes que a população de Petrolina, empregada neste estudo.

Existem diversas informações na literatura sobre P.macropilis. Entretanto, em nivel de campo, estas informações são bastante restritas. MORAES (1991) reportou-se ao uso desta espécie para o controle de T.urticae em roseiras no município de Holambra, São Paulo, prática que perdurou por vários anos em uso por agricultores 
locais. Com o início das exportações das rosas produzidas por aqueles agricultores, esta prática foi suspensa dado o elevado nível de sanidade exigido pelos importadores.

Os resultados obtidos neste estudo indicam a potencialidade do controle biológico de T.urticae com a liberação de predadores da família Phytoseiidae, o que foi também observado em outros países em condições de casa-de-vegetação e em nível de campo, com predadores de outras espécies (McMURTRY, 1991). Grandes quantidades de acaricidas são anualmente empregadas nas culturas consideradas neste estudo para o controle de T.urticae. A comprovação de uma forma alternativa viável de controle desta praga poderá implicar uma mudança desejável nos padrões normais de produção destas hortaliças no estado de São Paulo. É preciso entretanto comparar a eficiência dos predadores utilizados neste estudo com aquela de outras espécies que vem sendo utilizadas em outros países. Uma vez identificadas as espécies mais promissoras, seria então necessá-rio a comprovação da tecnologia em nível de campos de agricultores, onde o fator econômico tem um peso significativo na adoção da nova tecnologia.

\section{AGRADECIMENTOS}

A G.R. de Almeida, J.L. da Silva e J. A.H. Galvão pela inestimável colaboração prestada durante a realização deste trabalho.

\section{REFERÊNCIAS BIBLIOGRÁFICAS}

ARAUJO, W.F.; MORAES, G.J. de; DELALIBERA Jr., I. Biologia do ácaro Amblyseius idaeus (Denmark \& Muma) (Acari: Phytoseiidae). In: CONGRESSO BRASILEIRO DE ENTOMOLOGIA, 13, 1991. Recife. Resumos... Recife: SEB, 1991. p.1.

DENMARK, H.A.; MUMA, M.H. Phytoseiid mites of Brazil (Acarina: Phytoseiidae). Revista Brasileira de Biologia, Rio de Janeiro, v.33, p.235-276, 1973.

FLECHTMANN, C.H.W. Ácaros de importância agrícola. São Paulo: Livraria Nobel, 1985. 189p.

GARCIA, I.P. Estudos com Phytoseiulus macropilis (Banks, 1905) (Acari: Phytoseiidae) para o manejo de Tetranychus urticae (Koch, 1836) (Acari: Tetranychidae) na cultura de morangueiro (Fragaria spp.). Botucatu, 1992. 64p. Dissertação (Mestrado) Faculdade de Ciências Agrárias e Veterinárias de Botucatu/Universidade Estadual Paulista "Júlio de Mesquita Filho".
GONDIM Jr. M.G.C. Efeito da vegetação nativa no controle biológico de Mononychellus tanajoa (Bondar) (Acari: Tetranychidae), na Zona da Mata de Pernambuco e biologia de Neoseiulus anonymus (Chant \& Baker) (Acari: Phytoseiidae). Recife, 1992. 143 p. Dissertação (Mestrado) Universidade Federal Rural de Pernambuco.

HELLE, W.; SABELIS, M.W., ed. Spider mites: their biology, natural enemies and control. Amsterdam: Elsevier, 1985, v.1A, 405 p.

MCMURTRY, J.A.; SCRIVEN, G.T. Insectary production of phytoseiid mites. Journal of Economic Entomology, College Park, v.58, p.282-284, 1965.

MCMURTRY; J.A.; HUFFAKER, C.B.; VAN DEN VRIE, M.V. Ecology of tetranychid mites and their natural enemies: A review. I. Tetranychid enemies: their biological characters and the impact of spray. Hilgardia, Berkeley, v.40, n.11, p.331-390, 1970.

McMURTRY, J.A. Augmentative releases to control mites in agriculture. In: Dusbbek, F.; Bukva, V., ed. Modern Acarology. Praga: Academia. The Hague: SPB Academic Publishing, 1991, p.151-157.

MESA, N.C.; BELLOTTI, A.C. Ciclo de vida y habitos alimenticios de Neoseiulus anonymus, predador de ácaros Tetranychidae en yuca. Revista Colombiana de Entomologia, Cali, v.12, n.1, p.54-66, 1988.

MORAES, G.J. de. Controle biológico dos ácaros fitófagos. Informe Agropecuário, Belo Horizonte, v.15, p.55-62, 1991.

MORAES, G.J. de. Perspectivas para o uso de predadores no controle de ácaros fitófagos no Brasil. Pesquisa Agropecuária Brasileira, Brasília, v.27, p.263-270, 1992.

MORAES, G.J. de: MCMURTRY, J.A.; DENMARK, H.A. A catalog of the mite family Phytoseiidae. Brasilia: EMBRAPA, Departamento de Difusão de Tecnologia, 1986. 353p.

OATMAN, E.R.; McMURTRY, J.A. Biological control of the two-spotted spider mite on strawberry in Southern California. Joumal of Economic Entomology, College Park, v.59, n.2, p.433-439, 1966.

YANINEK, J.S.; MÉGEVAND, B.; MORAES, G.J. de; BAKKER, F.; BRAUN, A.; HERREN, H. Establishment of the neotropical predator Amblyseius idaeus (Acari: Phyt.) in Benin, West África. Biocontrol Science and Technology, Oxfordshire, v.1, p.323-330, 1991.

Enviado para publicação em 16.06 .93

Aceito para publicação em 25.08 .93 